of the cardiac vessels and the muscular fibres of the ventricles pursue a spiral direction from left to right downwards, and form left-handed spirals. The nerves consequently always cross the branches of the cardiac vessels and the muscular fibres nearly at right angles. The nerves invest the bloodvessels with elaborate plexuses, particularly the coronary sinus, which, as Dr. Pettigrew shows, is covered with a mass of ganglia and nerve filaments. The ganglia are most numerous on the coronary sinus and main vessels, but they also occur where the nerves cross the branches of the main vessels. In the former situation the ganglia vary as to size and shape; being sometimes large, sometimes small, sometimes stellate-shaped, sometimes quadrangular, and sometimes triangular. In the latter situation the ganglia are spindle-shaped and more uniform. From the foregoing account it will be obvious that the cardiac nerves and ganglia are in contact with the bloodvessels and muscular fibres at innumerable points; so that they are in a position either to exert or withhold stimulus, and consequently to regulate the nutrition and movements of the heart. Dr. Pettigrew has examined the ganglia of the heart microscopically, and shows that they are composed for the most part of unipolar and bipolar nerve-cells which contain nuclei, and are in communication with delicate nerve filaments. The nerve filaments in some instances cornmunicate with irregular aggregations of cells; at other times they conduct to and from spindle-shaped masses of cells; while in a third, and not unfrequently, they terminate in rounded or bulbous masses of cells. The presence of ganglia and nerves in such quantity on the surface and in the substance of the heart in part accounts for the movements of the organ when cut out of the body. Dr. Pettigrew does not, however, refer the movements of the heart entirely to its nerves; for he explains that rhythmic movements occur in plants and in cilia where no nerves are present, and in the embryonic heart while yet a mass of nucleated cells and before it contains either muscular fibres or nerves. He ascribes the movements to the vitality of the ultimate elements of the heart, to healthy nutrition, and the power of moving inherent in all living substances. He regards the nerves as co-ordinating, rather than causing, the movements of the heart. He enters at considerable length into the several explanations given of the rhythm of the heart, and tabulates the various theories propounded as to the function performed by the pneumogastric and sympathetic nerves, particularly those branches proceeding to the heart. Their inhibiting and depressing action is also alluded to. Dr. Pettigrew does not regard the blood as the stimulus to the heart. He states, and very properly, that if the presence of this fluid within the heart caused its several compartments to contract they would do so as soon as the blood entered, and long before the compartments were full. But the ventricles, as already explained, completely empty themselves of blood during the systole, so that they must open spontaneously before a fresh supply of blood can be admitted. The opening of the ventricles causes the blood to flow into the ventricular cavities, but the presence of the blood in the ventricular cavities is not the occasion of the opening of the ventricles, this being a spontaneous vital movement. That the presence of the blood is not necessary to the movements of the heart is proved by the fact that the heart beats regularly both within and without the body when it is deprived of blood. It also pulsates rhythmically in the embryo before it contains blood. These and other facts of a like nature induce Dr. Pettigrew to believe that the theory of irritability as applied to the heart is more or less fallacious.

Such are $\mathbf{a}$ few of the points touched upon. If time and space had permitted, we might have alluded to numerous others not less interesting and equally important. It will not be too much to say that Dr. Pettigrew's lectures will form an era in the history of the circulation. In order to be appreciated they must be carefully perused. They are arranged in three principal divisions-viz., Circulation in Plants, Circulation in Animals (Invertebrata), and Circulation in Animals (Vertebrata). Under the first division the following among other subjects are discussed: endosmose and exosmose as adjuncts of the circulation; the vessels of plants, their function; points of resemblance between the vessels of plants and animals; respiration of plants and animals ; cells of plants, their nature and function; the intra-cellular circulation in plants; the lactiferous circulation in plants ; the forces which produce the circulation in plants; organic forces a modification of inorganic ones; motion a condition of matter, \&c. \&c. Under the second division come: respiration and assimilation, as bearing upon the circulation; digestion and circulation; how the circulation connects the organic and inorganic kingdoms; ciliary movements and currents ; circulation in the leech contrasted with that in plants ; circulation in the star-fish, spider, insect, lobster, fish, Brachiopoda, Gasteropoda, cuttle.fish, \&c. \&c. Under the third division come: circulation in the fish, aquatic reptiles, frog, Lacerta ocellata, python, crocodile, mammal, \&c.; the fotal circulation; the structure, properties, and function of the lymphatics, bloodvessels, and heart; the structure and function of the valves, and the distribution of the cardiac nerves and ganglia.

We are glad to learn that arrangements are being made for a republication of these important lectures in England and America. They cannot fail to take a permanent place in medical literature, the more especially as they are illustrated by a profusion of engravings, for the most part original.

\section{A SHORT ACCOUNT OF THE}

\section{CASE OF THE LATE MR. LUTWIDGE, Commissioner in Lunacy.}

BY WM. MARTIN COATES, M.R.C.S., SUBGEON TO THE BALISBURY IN FIRMABY.

ON the 21st of May, 1873, Mr. Lutwidge, aged seventytwo, apparently in excellent bealth, and possessing a fine constitution, was suddenly attacked from behind by a criminal patient in Fisherton House Asylum, and wounded in the right temple just above the zygoma. The weapon was a nail, four inches in length; and the murderer had fixed to its head a piece of a carpet watch-bag, which gave him purchase, and so enabled him to drive the nail with great force. Mr. Lutwidge did not fall; he was prevented, apparently, from doing so by the frame of the doorway through which he was passing at the moment of the attack; but he complained of feeling tottering on his legs. It was observed by Mr. Wilkes, the medical commissioner who was present, and by an attendant of the asylum, that his mouth was immediately drawn to the right side.

I saw him at 3.30 P.M., about twenty minutes after the event. $\mathrm{He}$ was reclining on a sofa, apparently asleep, and breathing heavily. On being told that I had come to see him, he roused up at once, and told me that one of the patients had struck him on the side of the head, and that he felt a little pain in the right temple and right eye. He made light of the injury. I found a small vertical wound, about a third of an inch in length, above the zygoma, and an inch and a half from the outer edge of the orbit, from which a few drops of dark biood slowly oozed. Around the wound there was slight swelling and ecchymosis. His mouth was drawn to the right. The nail had evidently penetrated the squamous portion of the temporal bone. He protruded his tongue without deviation to right or left; 
this he continued to do as long as he remained conscious. His pulse was quiet and regular. We observed that immediately he ceased to talk he fell into a very deep sleep. The pupils were contracted, and acted very slightly.

He was removed to the White Hart Hotel, Salisbury, at 5 P.M., and I, with difficulty, induced him to go to bed, so little ill did he feel. $\mathrm{He}$ would not accept assistance in undressing, but fumbled a good deal with his buttons. He was given at his request some tea, which he swallowed easily and relished. Water dressing was applied to the wound and absolute quiet enjoined. At 7 P.M. I saw him again. He had then complete hemiplegia of the left side; pulse 68 , moderate in power, and slightly irregular; pupils the same. He was quite sensible, but talkative; his eyelids remained closed during my visit. He was still disposed to fall into deep, snoring sleep; he swallowed with difficulty. Prognosis very unfavourable. Diagnosis, wound of a vessel or vessels within the cranium, with hæmorrbage and consequent pressure on the right hemisphere of the brain. This conclusion was come to from the steadily augmenting paralysis of the left side, from a very small beginning to complete hemiplegia. There was anæsthesia and absence of reflex action in left arm and left lower extremity. My colleague, Mr. George Tatum, saw him with me in consultation at 8 P.M. Mr. Wilkes, the friend and fellow-commissioner in lunacy of Mr. Lutwidge, was associated with us. The question of trephining was of course considered, but unanimously negatived, as we all felt persuaded that the symptoms pointed to bæmorrhage within the cranium.

May 22nd.-8 A.M. : No improvement. He passes urine involuntarily; has evidently lost the vision of the left eye; pulse the same; pupils contracted and sluggish ; he is still alternately talkative and drowsy. At 10 A.Mr. Sir James Paget saw the patient with me. $\mathrm{H}_{e}$ quite coincided with our prognosis, diagnosis, and treatment by perfect rest, nutritious fluid diet, and the relief of symptoms as they arose, if possible.

From this time to his death, on the 28th, the only new circumstances that occurred were, that on the fourth day from the accident he spontaneously opened his ejes, had some return of reflex action in the lower extremities, and he swallowed fairly well. In other respects the same symptoms went on increasing from day to day; he became more talkative and less coherent, and his sleep more and more resembled coma, until at last the former ended in muttering delirium. His pulse became more and more intermittent, his tongue drier, and during the last twelve hours he was comatose, and his pulse rose to 120 in the minute, and was very irregular. He died on the 28 th of May at ten minutes to 7 P.M. His bowels were sluggish from the time of the injury, but yielded to medicines and enemata. $\mathrm{He}$ could not control the sphincter of the bladder after the 21st, and this viscus never contained throughout his illness any appreciable quantity of urine.

During the whole period of his illness he never complained or uttered an irritable word, and until the 26 th he told anecdotes which we found to be literally correct. $\mathrm{He}$ often referred to his accident in a jocular, amused way, but never evinced the least angry feeling against his as. sailant. The external wound healed by the first intention.

Autopsy, twenty-one hours after death.-I was assisted in the post-mortem examination by my friend Mr. Biggs. The external wound had so completely healed that it had to be looked for carefully. There was slight extravasation of blood in the track of the wound, which passed through the squamous portion of the temporal bone and membranes into the right hemisphere of the cerebrum. The opening in the bone would not quite admit the tip of the little finger. There was lymph spread over the arachnoid, covering the upper surfaces of both hemispheres, and this membrane was throughout vascular. A portion of skull in its entire thickness had been driven before the nail, and was lying in apposition and parallel to the cranium just anterior to the opening. It was kept in this position by a small piece of dura mater attached to it. There was just opposite the wound a rent, measuring an inch in length, on the surface and of the snbstance of the right cerebrum, through which a black coagulum protruded. On slicing the brain, we found a large cavity in the centre of the right hemisphere, running from within half an inch of the anterior to within an inch of its posterior extremity. This cavity was wholly occupied by a large coagulum, an inch and a half in thick. ness at its centre, and about an inch at its extremities. It had penetrated into the right lateral ventricle. The brain surrounding the clot was unnaturally soft in texture, and of a deep-pink colour. We could not discover the source of the hæmorrhage. There was an ounce of dark fluid blood between the right hemisphere and tentorium cerebelli. The whole base of the brain was stained by dark-coloured fluid blood. The left hemisphere was normal.

The post-mortem appearances explained most of the symptoms, and showed how fortunate was our decision not to trephine. Such a proceeding would have caused the patient great agony, and could not have possibly benefited him, as it was evident that the cause of death lay in a large clot occupying the centre of the right hemisphere, and making pressure upon the brain-substance itself.

The violent death of this valuable public servant by the deliberate act of this miscreant, who perfectly knew what he was doing, having carefully planned and most cunningly carried out his design, naturally and rightly excites our grief and indignation; and it certainly raises the question whether all deliberate and conscious murderers, sane or insane, should not be destroyed in the true interests of society. This miserable and fretful criminal lunatic can be of no use in this world to anyone, is a perpetual menace and danger to all who approach him, and will be a burthen on the nation as long as he lives. To Mr. Lutwidge a death so painless from beginning to end, at the age of seventy-two, incurred in the performance of a beneficent duty, may, I think, be considered a happy termination of a useful and honourable career.

\section{THE DUBLIN HOSPITALS.}

THE Board of Superintendence of these hospitals lately issued their fourteenth annual report. While engaged in the work of inspecting the various establishments, careful inquiry was made by the Board into the conditions and administration of each institution, and into the comfort and general welfare of the patients. Commencing with the Westmoreland Lock Hospital, we find that during the past year 753 patients were admitted, the mortality being 1.43 per cent. At this hospital the patients are required to wear the hospital uniform, and would otherwise appear to be submitted to a tolerably strict discipline, with which they, however, cheerfully comply. The beds consist of straw packed in coarse ticking, and the visitors very properly suggested that this should be superseded by cocoa-nut fibre or hair mattresses. At Steevens' Hospital, 2332 patients were admitted, 71 being small-pox cases, of which 8 died. The general mortality was 266 per cent. The upper storey of this institution is entirely devoted to the treatment of constabulary patients. At the Meath Hospital 1144 patients were admitted, the mortality being 6.46 per cent. Fifty-six of the cases were due to small-pox, of which 14 died-a large percentage. The Cork-street Fever Hospital admitted 1481 patients during the year, with a mortality of 13.82 per cent. The small pox cases amounted to 427 (including 92 not vaccinated), of which 104 died, or $24 \cdot 35$ per cent. This is also a large percentage of deaths, and is probably explicable by the defective sanitary arrangements in that portion of the hospital devoted to the treatment of small-pox, and concerning which the Board found just cause of complaint. The Hardwicke Fever Hospital admitted 1348 patients, the mortality being $13 \cdot 48$ per cent. Of the admissions, 603 were small-pox cases (505 vaccinated), of which 121 died, or 20.06 per cent. The Whitworth Hospital admitted 870 patients, the mortality being 8.68 per cent. The Richmond Hospital admitted 1172 during the year, the mortality being 2.82 per cent. The general arrangements of this institution would appear to be excellent; cooked food is conveyed to each ward in a tin can, the under compartment of which is filled with boiling water; this keeps the meat hot during transit to the several wards. A movable bath mounted on a strong frame with wheels is provided, which enables a patient to take a bath at his bedside. At the Rotundo Lying-in Hospital, 1321 patients were admitted into the labour wards and 200 into the chronic wards, the time spent in 